PART 5

A PSYCHOSOCIAL MATERIALISM 


\title{
12. SOCIALIZATION, LANGUAGE, AND SCENIC UNDERSTANDING
}

\author{
Alfred Lorenzer's Contribution to a Psychosocietal Methodology
}

\section{INTRODUCTION}

The chapter is a guided tour to Alfred Lorenzer's proposal for an 'in-depth hermeneutic' cultural analysis methodology which was launched in an environment with an almost complete split between social sciences and psychology/psychoanalysis. It presents the background in his materialist socialization theory, which combines a social reinterpretation of the core insights in classical psychoanalysis - the unconscious, the drives - with a theory of language acquisition. His methodology is based on a transformation of the 'scenic understanding' from a clinical to a text interpretation, which seeks to understand collective unconscious meaning in text, and is presented with an illustration of the interpretation procedure from social research. Then follows a brief systematic account of key concepts and ideas interaction forms, engrams, experience, symbolization, language game, utopian imagination - with an outlook to the social theory connections to the Frankfurt School. The practical interpretation procedure in a Lorenzer-based psychosocietal research is briefly summarized, emphasizing the role of the researcher subjects in discovering socially unconscious meaning in social interaction. Finally an outlook to contemporary epistemological issues. Lorenzer's approach to theorize and research the subject as a socially produced entity appears as a psychosocietal alternative to mainstream social constructivism.

\section{THE LANDSCAPE BEFORE AND AROUND LORENZER}

In their important and influential book The Social Construction of Reality, Berger and Luckmann (1966) seek to create a holistic social theory, which recognizes the social significance of human agency and consciousness by synthesizing the macrosocietal perspective of knowledge sociology with G. H. Mead's micro-perspective of meaningful agency and social psychology. In an interesting note they quite strongly ban recent attempts to synthesize Marxism and psychoanalysis:

There is a considerable irony in the fact that, of late, neo-Marxist theoreticians have been seeking a liaison with Freudian psychology (which is fundamentally 
incompatible with the anthropological presuppositions of Marxism), completely oblivious of the existence of a Meadian theory of the dialectic between society and the individual that would be immeasurably more congenial to their own approach. For a recent example of this ironic phenomenon, cf. Georges Lapassade, L'entrée dans la Vie (Paris, Eds. de Minuit, 1963). (Berger \& Luckmann, 1966, p. 218, note 25)

Symbolic interactionism, inspired from phenomenology, and action sociology primarily sees society as conscious and meaningful agency in the life world and Berger and Luckmann (1966) argue that knowledge sociology provides the understanding of how agency makes up the foundation for societal structure through a process of sedimentation and/or reification. Obviously they see Mead's social psychology as the concept best theorizing the subjectivity of agency. Their account of socialization is almost exclusively about the societal imprint on the individual agent - cf. the reference to Mead. The role of subjectivity in history (and B\&L's theory is actually also a historical account of the emergence of society) remains largely un-theorized in its own right, and they explicitly and very quickly abstain from elaborating "a genuinely dialectic social psychology" which they admit would be the proper alternative to the alliance they despise (p. 230, note7).

They continue, in another note:

There is a fundamental dichotomy between the conception of man as a selfproducing being and conception of 'human nature'. This constitutes a decisive anthropological difference between Marx and any properly sociological perspective on the one hand (especially one that is grounded in Meadian social psychology) and Freud and most non-Freudian psychological perspectives on the other. (p. 220, note 7)

It is a bit strange, in view of Berger and Luckmann's ambitious project, to launch such theoretical demarcations in a note. I tend to see these comments as symptoms of a latent awareness of a problem - a stone in the shoe - a problem that has not been thematized before but presses itself into the horizon of Berger and Luckmann's otherwise extremely embracing and integrative work.

The point about Freud is beyond dispute, but also obsolete. Apart from the one work mentioned we may after all assume that most of the psychoanalysts that European Marxists approached in the 1960's already theorized psychodynamics socially, and were politically and theoretically committed to an emancipatory thinking in which human agency and consciousness was essential (e.g. Mitscherlich, 1963). Berger and Luckmann might also have noticed, at the opposite side of the gorge, Erikson's (1950) development of a cultural psychology as an attempt to understand the dialectic between the individual and society on a psychoanalytic ground - although in the first place limited to child socialization and kept within a developmental psychology framework. In Europe the ethno-psychoanalysts simultaneously analysed the dialectic between individual and society in the remote Dogon-culture 
(Parin, Morgenthaler, \& Matthéy, 1963), de facto defining personality structures as a result of cultural environment - later generalized into a revised psychodynamic theory (Parin, 1983).

These comments from 1966 remind about the fundamental challenge connected with the conception of subjectivity and the relation between individual and society in a social science landscape where the disciplinary domains separated knowledge of the individual from knowledge about society. It may also reflect an enduring prejudiced tendency to see psychoanalysis as a closed community, not recognizing the very fundamental ongoing discussions between Freudian psychoanalysts and several re-interpretations of the origins of the inner psychic structures. In this landscape it appears even more remarkable, that Alfred Lorenzer developed a theory which took the challenge to develop a social reinterpretation of Freud's basic ideas on a materialistic ground which might easily be mistaken for a biological and deterministic in the way Berger and Luckmann (1966) obviously see the psychoanalysis.

When we have focused on Lorenzer within a broad and multiple tradition of combining a Marxian analysis of society (Frankfurt School critical theory) and psychodynamic theorizing of the subject it has two interrelated reasons. One is that he has been particularly productive for the development of a methodology of empirical qualitative research. The other one is that his socialization theory by focusing on language at the same time as maintaining a clearly materialistic view on the body as well as on the socio-material structure of society has provided a key contribution to theoretical and epistemological issues of social science, that have become articulated much later. We shall come back to this at the end of this chapter.

\section{ALFRED LORENZER'S INTELLECTUAL JOURNEY}

Alfred Lorenzer (1922-2002) came from the background of being a medical psychiatrist, trained in psychoanalysis on a Freudian background. As a doctor and psychoanalyst, he took an early interest in societal critique and cultural theory, taking to task the Frankfurt School of thought and its critical theory. Understanding subjective structure as influenced by societal conditions increasingly came to dominate his theoretical thoughts. As early as 1970 , he criticized the psychoanalytical concept of 'symbol' (1970a), placed it in a linguistic science context (1970b) and subsequently expanded the application of it into socialization theory (1972), epistemology (1974) and cultural analysis (1986). The red thread of his contribution is to provide a ground for a social interpretation of the basic psychodynamic forces without giving up the radical insights in Freud's theory. The first step in this chain from psychoanalysis to societal theory was an interactionist theory of socialization (1972) in which he reconceptualized these psychodynamic forces which in classical psychoanalysis since Freud were seen as biological, result of natural drives. Lorenzer established a dialectical theory according to which they were results of the social interaction, in the first place between infant and mother (caring person), and thereby also enabled an understanding of the unconscious - the most radical element 
in psychoanalysis - as a result of the symbolic interaction. The following works developed methodological ideas for an endogenous understanding of the subjective dimensions of social interaction and language - quite opposite to the direction Freud took in meta-psychological and cultural theory.

The point of departure in Lorenzer's relevance to current theoretical, social and political issues is the Copernican turn of the Freudian theory which had been initiated by a number of psychoanalysts: In continuation of Freud he analyses the development of the structure of personality as 'representing experiences of bodily interactions' (1972, p. 17). But whereas Freud saw their impact in the psyche, as predominantly distortion, disturbance and blocking of (biological) drives in the subject Lorenzer sees these social interactions and the bodily experiences of them as a dialectical shaping of the drives into a subject, and the resulting psychic dynamics as highly social phenomena. The individual sensual experiences of social relations and meanings in immediate interaction are connected with the wider social world in the form of symbols. The issues of psychotherapy, disturbances of the psychic development, were reinterpreted as disturbances of the possibility to symbolize individual sensual experiences in socially recognized language. Lorenzer's critical reinterpretation of the psychic disturbances are expressed in the early book titles 'Kritik des psychoanalytischen Symbolbegriffs' (Critique of the Psychoanalytic Concept of Symbol) and 'Sprachzerstörung und Rekonstruktion' (Language Destruction and Reconstruction) - both from 1970. On the one hand enabling a reinterpretation of the psychotherapeutic task, this critique on the other hand opens a new way of theorizing the psychodynamic aspects of societal relations. Symbolic/cultural meaning (for the individual) is seen as a complex mediation of social interaction and sensual experience, and has conscious as well as unconscious aspects. Later Lorenzer developed further his key concept of 'interaction forms' to understand the inner, pre-linguistic experiences of practices and relations. These interaction forms are connected with the socially recognized language to form symbolic interaction forms, and the developing of capacity for symbolic production can be seen as an integrated aspect of socialization. This understanding of the early socialization process enables Lorenzer to see language, interaction and bodily (drive) processes in their wider societal context - and we can add an epistemological perspective: In the context of a constructivist social science it enables us to see how ideas about societal relations are embodied in the individual socialization. Lorenzer's thoughts on the role of language in subject constitution build on the theorem of language games, which he took up from the works of Ludwig Wittgenstein and developed further. Language is anchored in concrete social practice in a dialectic unit of language use, everyday life practice and view of the world (Weber, 2010). Language games are thus defined as the interface at which subjective and objective structures interact. The question of the constitution of language games is, therefore, also one which addresses the constitution of the relationship between individual and society. Looked at in this way, language and awareness are inseparably linked with social practice. If the constitution of language games is seen as integral to the development 
of subjective structures under objective conditions, then the individual subject can be understood and deciphered using its ex ante social reference.

Lorenzer's contribution to the methodology gains a wider perspective by theorizing the genesis of the correspondence between unconscious dynamics in the subject and unconscious or unintended dimensions of societal and cultural processes. What is in the first place mainly a material theory of socialization - which unlike many other theories does not see the social shaping of the individual as assimilation to social structure - is in the second place a radical epistemology of societal dynamics. Lorenzer's theory of language games and his meta-psychological and methodological notions are closely linked with the search for opportunities for epistemic reconstruction of suppressed social relationships, which are (societally) imprinted in the (many individual) psyches and in their interaction. Lorenzer in brief draws the attention to the hermeneutic methodology of psychoanalytic understanding. The immediate inspiration is offered by an interpretation of interaction and cultural meaning in a way inspired by psychoanalytic interpretation, namely 'scenic understanding' whose further methodological foundations and methodical implementation will be taken up further in this chapter. Lorenzer separates the methodological principles of psychoanalysis simultaneous attention, free association and the concepts of transfer and countertransfer - from the clinical context of doctor-patient relationships, and transfers them to social and cultural scientific practice. He thus emphasizes the methodological experience as opposed to direct transfers of theoretical models since, in his view, these cannot be transferred from one field to another.

The socialization theory was Lorenzer's first distinguishing contribution. It builds the theoretical foundation for the development of a psychosocietal interpretation method with inspiration from the psychoanalytical interpretation of individuals. During the 1970's his work was widely cited and read both in Germany and abroad (notably the Scandinavian Countries) and today, his ideas continue to inform a vigorous tradition of cultural analysis and social research (Leithäuser \& Volmerg, 1988; Leithäuser, 1977; Morgenroth, 1990, 2010; Bereswill 2008; Lorenzer, 1970, 1971, 1972, 1974, 1977, 1986, 2006; Prokop et al., 2009). A number of Scandinavian, especially Danish, researchers have published work directly referring to this tradition, or using the methods more or less in accord less in accordance with it, most of it published in Danish. For an overview see Weber (1996, 2007, 2009, 2010); Salling Olesen (2004, 2007a, 2007b, 2011) and Weber and Salling Olesen (2001, 2002). However, Lorenzer is little known outside German speaking communities. To the best of my knowledge, only one small example of his work has been published in English translation (Lorenzer \& Orban, 1978). Recently another text has been introduced, translated and posted in the internet (Lorenzer, 1981; Schaffrik, 2002). But 'in-depth Hermeneutic analysis' remains largely unfamiliar to English-speaking audiences. When we in a joint research network explored the parallels between this tradition and pioneering work in the Anglophone psychosocial research (e.g. Hollway \& Jefferson, 2000), the language based a-symmetry was obvious and it 
seemed imperative to provide access to some of the non-Anglophone research tradition to a wider audience.

In the following we will concentrate on the methodological impulse from cultural analysis in social research. In a late stage of his work, in the key text in 'Kulturanalysen' (1986), he coins the notion of 'Tiefenhermeneutische Kulturanalyse', which focusses on the systematic reconstruction of unconscious meaning dimensions in analysis of literary texts. This text played a significant role in the intensive multilingual discourse in our research network between Danish, German and British researchers, of which half were nonGerman-speaking, facilitated by a translation (by Mechthild Bereswill and Christine Morgenroth, unpublished). The book as a whole is a collective work with a number of case studies, mainly on literary texts, but also one (by Søren Nagbøl) extending the horizon to architecture. 'Kulturanalysen' (Cultural Analyses) summarizes the contribution of his interaction theory extensions of psychoanalysis from the 1960s and 1970s and may be read as the key text to the complex meta-theoretical ideas that have proven useful in empirical studies in many areas of social life under the general heading of 'Tiefenhermeneutik' (in-depth hermeneutic).

Lorenzer believes this is where what he calls the 'hard and provocative work' (1986, p. 16f.) in the psychoanalytical critique of society and culture enters. He sees the position of psychoanalysis between differing disciplines against whose borders it grates. The 'conflict potential' of a psychoanalytic approach traditionally arises from revealing the social constraints a subject faces, but, more importantly, how desires and past experiences may influence e.g. cultural productions like literature. Lorenzer here emphasizes the difference between a therapeutic and a social or literary discovery process: 'Where therapy is concerned, the origin [of the subject] is investigated by asking: how did the conflict arise in the case of this individual? In cultural analysis, however, the question is: what kind of conflict are we dealing with? The focus is on the conflict between unconscious desires and conscious values' (ibid., p. 67).

In fact the notion of conflict in the last sentence might be a bit misleading in translation - in Lorenzer's German text it reads 'Auseinandersetzung zwischen', which implies 'intensive interrelation' or 'interaction between' in the sense of connecting rather than a conflict between two independent opposing parties, or in philosophical terms: It is an intrinsic rather than an extrinsic relation. In Lorenzer's thinking the relation between the conscious and the unconscious levels of the subject is more complex than just being a conflict. They are both influenced by experiences in the past, and conscious and unconscious dynamics interrelate in the ongoing processing of cognitive and emotional aspects of experiences. Unconscious dynamics which refer to contradictions experienced in the past (and hence of cultural and societal nature), which may have become unconscious, while their conflictual meaning may have been transferred to another content are particularly important in the original therapeutic context. But the very existence of unconscious dynamics which are of cultural and societal nature, and that they remain in interaction with 
meaning making and conscious engagements in the present is the important insight for interpretation of social interaction and cultural meanings. Lorenzer and his colleagues eventually demonstrates this potential in interpretation of arts products, but the insights in societal nature of the subjective processes opens a door to interpret not only cultural products, but to interpret interviews and other qualitative material from empirical research of a wide range of more profane social practices and spheres.

\section{IN-DEPTH HERMENEUTIC CULTURAL ANALYSIS}

Alfred Lorenzer's introduction article 'Tiefenhermeneutische Kulturanalysen' in the book Kulturanalysen (1986) is as close as he comes to spell out a methodology. Basically he points to the hermeneutic (interpretational) nature of the form of understanding which is used in psychoanalytical therapeutic practice, generalizes it in what he calls the 'Scenic Understanding', and comments the nature of this transformation. The particular value of these thoughts mainly become evident in reflecting a research practice by means of researchers subjectively engaging in the interpretation, tracing aspects of social relations which are not immediately visible and may be not even conscious for social actors. For this reason we developed an interpretation process example of a text which had been presented in the research group. In the following this sample scene and our interpretation of it will be used for illustration linking our interpretation steps along this short sequence with central passages of Lorenzer's text. As it usually is the case the interpretation process became an illustration in itself - interpretation requires the engagement of the interpreters in an interaction with the text which transcends the obvious meaning of the text, and hence becomes part of the interpretation in itself. We took up a brief scene presented in the Dubrovnik workshops by our British colleague Joanne Whitehouse, who used qualitative methods to study a popular yet highly contested form of media product the reality TV program Big Brother, which has sparked heated debate not just in Great Britain (Redmann \& Whitehouse, 2008). We wanted to illustrate Lorenzer's methodological and meta-theoretical reflections using an empirical example from the discipline of cultural studies to show what scenic understanding might mean for empirical analysis.

We analyzed the reaction of a female viewer as portrayed in the following scene. We interpreted the scene as a representation, not as a factual account that can be read at face value, and not as a transparent subjective expression. We assumed that such representations are based on shared cultural experience and provide us with access to subjective and social dynamics, which we attempt to reveal with the aid of Lorenzer's thinking.

The structure of this type of program is a closed group who is monitored in their interaction, and the viewers are invited to vote about who should be sent home at each stage of the show, An interviewee, Lou, reported (to Joanne) that she had been watching an episode of Big Brother. One of the housemates, Jonny, offered a second housemate, Adele, a cup of coffee. Adele refused in a friendly fashion but 
as Jonny walked away she mouthed the words "Fuck off" to his retreating back. The interviewee, Lou, was so outraged by what she took to be Adele's two-faced behavior that she decided she would vote to have Adele evicted from the show and, moreover, that she had to do this straight away. Because her own phone was out of order she rushed from the house to use a public phone box on the corner of her street. Unfortunately, the phone box was occupied and, feeling increasingly frustrated, the interviewee started banging on the phone box door telling the person using it to hurry up. "I just wanted her (i.e. Adele) out", she explained in the interview.

At first glance the text we looked at irritates and confuses, displays a remarkable amount of emotion and contains a variety of action and interaction levels which all run together. It may also provoke normative reactions in the interpreter, not least as regards the contested TV format that attracts large numbers of viewers. The scientific and popular controversies concerning a program like Big Brother thus point to underlying issues of subject and society in the context of social change: on the one hand the age-old discussion about how much influence mass media has in guiding people's actions, on the other hand the much more interesting question about how the contents of the media engage with the subjective issues of the audiences.

The manifest meaning of the sequence is readily visible: we are witness to an emotionally loaded reaction in the context of a medially presented group player game. The structure of the constitutes a dual scene: contestants in the containers and contestants in front on the TV enter into a relationship with one another whereby the quality of their relationships is the key to further exclusion or inclusion of individual players. In other words, the publicly celebrated relationships between the inhabitants of the container give the viewers a chance to enter into a relationship which forms the basis for their decision on whether or not to vote for or against a particular contestant.

There are several simplistic interpretations of the scene which are near at hand (and the interpreting group did not evade the temptation in the first place): we could interpret it as a confirmation of a culturally pessimistic standpoint concerning the increasing degeneration of the mass media, or in a more or less psychological sense as an expression of a threatened if not damaged subjectivity which comes to light with the loss of key self-determination skills. Although different in focus they don't leave much space for understanding subjective agency. In a way they treat the social agent as a patient and diagnose his/her vulnerability for social conditions. Alfred Lorenzer provides the theoretical arguments for avoiding such premature classifications. In Lorenzer's work, we read that apart from the manifest and latent meaning levels 'texts' house an unconscious meaning dimension which we can enter as readers, as observers or as researchers.

The impulse in psychoanalytical therapy is to change the patient who is being analysed. In the reader-text relationship the opposite is the case. Here it is the reader/analyst who is subject to change. If the reader as an interpreter acknowledges the emotional power of the text and does not stand in awe of it, 
his consciousness will be changed - at least, this is the case if he does not abuse the text-reader relationship by simply reading into the text a pre existing and well known version of psychoanalysis. (Lorenzer, 1986, p. 28)

This distinction takes our attention in another direction. We concern ourselves with the emotional power of the text and thus with the relationships it offers to the readers. How do we as interpreters take up this offer? How do we react to Lou's description - normatively, amused or intrigued? This line of thinking may be easily accepted when dealing with 'fine arts' - it resonances discussions about the criteria of quality in poetry, e.g. - but here we deal with a profane narrative about profane television watching. Posing these questions to the interpreters of the short research scene led us away from commenting and classifying the actions in the actual text per se, and towards its emotional qualities and evocative power in relation to the reader. And further the question of the 'relationship between text and reader' applies to the relation between the Big Brother-show and its viewers, in this case to Lou. What is it that makes her act so impulsively? If we go by what she says, then contestant Adele's two-faced attitude is what made Lou want to vote Adele immediately off the show and head out to find a telephone. According to Lou, Adele's behavior, which she describes as two-faced and underhandedly aggressive, sparked her unbridled anger; she is openly aggressive and attacks another person within her action radius.

The theoretical distinction of Psychoanalysis is the theory of the unconscious (Freud, 1915). It is actually a more complicated theory about levels of (un) consciousness with grey zones and displacements, which in Freud's version is a precondition for the therapeutic process as well as for the interpretation of dreams. The first methodical issue is to gain access to this level, not with an individual therapeutic aim, but in order to understand its social meaning. The interpretation of texts, be they literary works, field notes or excerpts from interviews, also constitutes a multilayered scene. In the case in question, we reconstruct a dual scene in which various interaction dynamics overlay one another and create a new scene in which we as interpreters become involved relative to those dynamics. We find Lou's extreme over-reaction difficult to understand and tend to distance ourselves from it.

Lorenzer goes on to say that literary texts contain a provocation which goes beyond individual and biographically specific reception patterns and points to societal, collective motives and meaning substance:

The provocation lies in content in the text itself. As such, its impact goes beyond the individual, it is perhaps societal-collective (gesellschaftlich-kollektiv), possibly even spread over many epochs. The unconscious in literature under consideration, is a collective unconscious, although admittedly not in Jung's sense. It consists of praxis figures (Praxisfiguren), which - as it were demand to enter consciousness, and contains forms of life (Lebensformen), whose access to general consciousness has been barred and whose value, in consequence, has not been openly tried out. (Lorenzer, 1986, p. 28, our translation) 
In interactionist (social) reinterpretations of psychoanalytical theory, including Lorenzer's theory of socialization, the unconscious level is just as much as the conscious a result of life history experience of social interaction. For the same reason the unconscious is assumed to contain a potential for social imagination which goes beyond the actual state of consciousness - either because it contains interaction experiences that have later been excluded from consciousness, or because it contains anticipating ideas of something 'emerging' which has not yet been realized in social practice. Continuing the previous quotation Lorenzer says:

These not-yet-conscious (Noch-nicht-bewusst) praxis figures - as Bloch says - generate a utopian potential. It is the work of hermeneutics to reveal this utopian potential and, in so doing, to take a stand against petrified circumstances (versteinerte Verhältnisse). [...] Why do we prefer the term indepth hermeneutics to characterize this approach? The answer is: because the practice of in-depth hermeneutics is the distinctive feature of psychoanalytical interpretation. ... The in-depth element of the hermeneutic approach is only to be found in psychoanalysis and underlines the central subject of psychoanalytical enquiry: the unconscious. (Lorenzer, 1986, p. 28)

Lorenzer's understanding of the critical and utopian potentials in the unconscious articulates an important dimension in the thinking of critical theory or Frankfurt School. The Frankfurt School generally sees theorizing and critique as a key to social imagination and utopian ideas. And since this thinking is based on materialist assumptions it means that imagination is endogenous, i.e. must be discovered and articulated from within societal reality, as it is condensed in Adorno's argument in the positivist dispute:

But if theory is not to fall prey to the dogmatism over whose discovery scepticism - now elevated to a prohibition on thought - is always ready to rejoice, then theory may not rest here. It must transform the concepts which it brings, as it were, from outside into those which the objects has of itself, into what the object, left to itself, seeks to be, and confront it with what it is. (Adorno, 1969/1976, p. 69)

In Habermas' thinking the term of 'Ideology Critique' spells out the need to reveal endogenous potentials for societal change through a critical analysis of social realities themselves. Change does not come from above or from outside. But whereas Habermas first of all sees the key in deconstructing observation and reflection of 'petrified social relations' and the societal institutions which make up the guises of power, social inequality and reified relations Alfred Lorenzer looks for the potentials in socialized psyche, in the dynamics between the conscious and the unconscious. And this brings the argument back to the text:

Does this imply that the unconscious is the sole aim of psychoanalytical interpretation and that every 'manifest/apparent meaning', every deliberately 
intended meaning of the text the author makes, has no significance? Indeed not, such an approach would not justify the title of a psychoanalytical literary and cultural analysis. This collection of analyses shows that the manifest meaning in no way can be seen as a 'ladder', which can be put aside in the moment you have reached the goal 'deep down there'. (Lorenzer,1986 p. 29, our translation)

Lorenzer's theoretical deliberations point to socially taboo, degenerate lifestyles and utopian moments of social practice which while being unconsciously maintained also emerge to influence [our] conscious, for example with the help of literary texts. Their provocation, according to Lorenzer, lies in the fact that they transport aspects of a collective unconscious which forces itself into the conscious. On the one hand Lou's arguments concerning Adele's two-faced behavior lines up seamlessly with the socially accepted meaning pattern of good or bad behavior. But the emotional charge 'beyond the boundaries of language' in the vehement desire to be rid of the other woman goes far beyond such socially acknowledge configuration. To have Adele thrown off the show, Lou is prepared to throw an unknown stranger out of the telephone box.

So what is it that forces itself into consciousness? The TV show (cultural meaning) elicits unconscious desires and identifications (interaction forms) which influence the agency and produces an intense ambivalence. The reconstruction of this ambivalence helps to reveal the unconscious in the text. We will address the interpretation procedure in more detail later. For the time being, however, we will stay with the relationship between manifest and latent meaning and read what Lorenzer thinks:

... the distinguishing feature of psychoanalytical cultural analysis as an 'indepth hermeneutic' is about the recognition of an independent level of meaning below the meaning generating level of language symbolism. While the manifest meaning resides in the socially recognized figures of consciousness, a level of unconscious interaction forms (Interaktionsformen) is pushed into consciousness on the level of latent meaning. It is certainly the case that this level of meaning, 'excluded by consciousness and social consensus', is one in which psychoanalysis was originally interested, and which Freud counted to parapraxes. But, at the same time, the manifest text-meaning is still importantas the counterpart to what is concealed-forbidden. Manifest- and latent-text meaning construct a contradictory pair, which psychoanalysis must seek to resolve [aufzuheben hat]. (Lorenzer, 1986, p. 29, our translation)

For cultural analysis, when unconscious interaction forms are pushed to the consciousness it means that the latent meaning of a text offers a potential access to understand collective dimensions of the unconscious. Manifest and latent meaning are dialectically related because language use point to non-verbal or pre-verbal dimensions of social interaction as Lorenzer describes in the concept of 'unconscious 
interaction forms'. It does not mean that we can simply identify the unconscious and the non-verbal: unconscious meanings are in the text as latent meaning or meaning potentials.

If we look at the construction of the show - and numerous other shows of the same type - as performance of interaction, and at the same time an invitation to interaction with the viewer the point is that the show invites the viewer to exert some kind of control in the limited world in the container - and in this case make a moral judgment on the behavior of the figures in the show. However, he/she can only do it in the dichotomous form of voting out or in. You are not only invited to make a regressive simplification of complex issues, you are forced to do it, if you want to participate in the interaction. So the relation between the inner logic of the show and the seemingly extreme actions of the Lou - and in the second place the evocative power of the text in relation to the interpreting researchers - might be a key to trace the unconscious meanings. Lorenzer's attempts to characterize the unconscious:

The unconscious is a non-verbal, non-symbolic system of meaning, which is contrary to individuals' linguistic order ... It is

- 'autonomous', because it comes into existence within specific and concrete mutual exchanges and is therefore the inscription of this particular ontogenesis.

- 'systematic', because from the first moment in a life-history, one memory trace follows another each becoming interwoven with the other (organismisch)

- 'meaning'-full (full of meaning) because the engrams are simultaneously the sedimented forms of past social interplay and drafts for that of the future. (Lorenzer, 1986, pp. 46-47)

In this framework Lou's disturbingly excessive action that lends the scene structure can be interpreted as systematic and meaningful in the context of biographical patterns. Autonomous elements prove to be the physical action, leaving the house, the purposeful movement in space, the hammering against the door of the telephone box. The TV show seems to set a subject's past interaction experiences in motion, which defy any language based symbolization yet remain registered as a bodily experience of social interaction. The reactivation of these interaction forms happens not in the sense of simple repetition of old conflicts, but as part of a dynamic interaction between old, past and new, current interaction experiences. The unconscious meaning of the scene points to something which is unexpressed and yet symptomatic. In the first place it evaded the perception of interpreters and gave way to irritation and premature classification of the subjectivity of only one actor in the scene (Lou). This individual psychological interpretation saw impaired ego functions: reality checks and emotional control are rendered ineffective and an archaic breakthrough of revenge impulses.

But if we look at the scene in the context of its multilayered structure, a structural double bind comes to light which neither the contestant in the container nor the voting viewer (like Lou) can escape: friendly, polite and civil behavior stands in diametric opposition to the competitive nature of the game and the dilemma it entails. 
Against this backdrop, Lou's rather excessive reaction can be seen to perform the role assigned to her by the TV-show. But they may also encompass anticipations of future behavior and interaction scenarios - imaginations about a transparent and preferably dominance-free communication - her reaction is a response to the unfulfilled desire for civility towards others, which Lou believes Adele is failing to demonstrate. Paradoxically she is driven to the opposite extreme and resorts to violence herself.

This interpretation of the unconscious in the text refers to experiences prior to the development of the ability to symbolize, yet they retain their effectiveness in scenic arrangements. But it does not mean simply that unconscious/conscious is the same as pre-language/linguistic - the relation is more complex:

The term 'configuration of practice figures' (Gefüge von Praxisfiguren) refers to the following characteristic. The interplay from which memory traces (interaction-forms) emerge is nothing but the exchange of gestures, bodily movement, and socially shaped and significant body processes: it is 'practice'. Every interaction-form is part of this practice, and therefore encompasses but goes beyond language. Practice as a whole is to some extent, submitted to the rules of language, but also partly resistant and reluctant, or is part of something utopic not-yet-conscious, i.e. part of human behavior that has not become encompassed in language. (Lorenzer, 1986, p. 47, our translation)

But how do we store these non-language-related memory traces, and how can we approach them in the interpretation? The following section explains Lorenzer's theory regarding the constitution of the scene in the context of intra- and intersubjectivity and the role played by the body and language. The following section returns to the methodological implementation in 'scenic understanding'.

\section{ENGRAMS, INTERACTION FORMS AND THE LANGUAGE GAME}

At a very early stage in his theoretical writings, Alfred Lorenzer meant that interaction experiences become embodied during the embryonic phase and the first few months of life. Thus, through the body's senso-motoric reactions, they help to shape specific and later-life experiences. Such interaction patterns which become ingrained in the body stand for an entire lifetime in a constant dialectic with the discursive demands of the social environment which are subsequently communicated through language. The start of this development in very early childhood is both a physical and a holistic process based entirely on sensory perceptions. In Lorenzer's own words, this means that:

The 'visual', 'tactile', 'acoustic', denote modes of sensory reception, which are directed by the central nervous system from the periphery of the body and which are then stored in precisely defined 'areas of the brain' [...] The inscription of these visual, tactile and acoustic impressions happens via 
'engrams'. These engrams are 'memory traces' in Freud's terms. Although this process is common to all infants, of course, the engrams of a single person are the memory traces of his or her experience as a particular individual. They have an individual profile. Just as Freud (1891) pointed out, in front of his time, in his book on Aphasie, that cerebral physiological functions and 'psychological' content cannot be separated it is obviously the experiences of the memory traces which are codified as engrams. And this means that the contents of memory (which is, of course, social) modifies the brain's physiological structures of the nervous system. And of course the memory traces combine into ideas of objects. And like the sensual impressions - visual, tactile, acoustic - combine into an idea of object, likewise will the objects that are perceived in different situations combine to form definite and concrete scenes. But this is expressed inaccurately: Of course it is the scene which is the immediate subject of the infant's experience. An awareness of individual objects only emerges from the scene gradually, and may later, in differing situations, combine to form well defined poles and stable figures within the scenic Gestalt. (Lorenzer, 1986, pp. 41-42, our translation)

Memory traces are non-verbal references to life practice, of experiences. These experiences are based on the efforts to achieve pleasure and avoid un-pleasure. Lorenzer emphasizes the 'bodilyness' of these processes. Lorenzer's theory of the language development and the notion of scenic understanding are actually in this sense coming close to contemporary cognitive science and the new synthesis between 'human' and 'biological' understanding of the brain (Lorenzer, 2002). Looked at today, he anticipates a paradigm shift: the current overriding view of the brain as a holistic system of complex information processing processes (Peled, 2008; Leuzinger-Bohleber, 1998). In memory research, embodied cognitive science has moved away from the notion of the human brain being a kind of computer designed to process information. Memory is now understood as an active process involving the entire organism and based on senso-motoric emotion coordination processes which occur in direct relationship with constantly adapting re-categorization processes. In Lorenzer's terms, this means that a child's early experiences of stimulusresponse games with its mother and other close individuals are retained as memory traces, as specific interaction forms. They are a lasting, natural impression of genuine social interaction forms in the subject. This is what Lorenzer calls 'socialized nature'.

But how do single memory traces become a configuration of many which evolve into life experiences and a complete life world? The notion of the scenic primacy poses the question the other way round. Experience is holistic, strongly shaped by sensory impressions and by satisfying (or their opposite) experiences. "The scene takes shape step by step through alternating and mutually constitutive interactions between changing and unchanging modes of experiences."

The self-correction in the quotation is interesting - it seems that Lorenzer here moves from one way of seeing the development of consciousness - as a combination 
of sensual elements into images of objects - to another, more holistic, in which an undifferentiated scenic experience oriented by the subject-to-be - gradually evolves through differentiation to become more detailed and stable object images, and it seems as if the self-correction is a trace of this theory development. The new conception aligns with empirically based knowledge about infancy development (Stern, 1985).

The process described always involves bodily processes:

If we take bodily processes into account, three aspects of the scenic become apparent

1. The imprint of situational experience (Situationserfahrung) is assimilated by an internal ensemble of tactile, acoustic etc. receptors. Likewise the receptor ensemble depicts the panorama of real impressions in the internal scenic composition of the engrams.

2. Even if not from the first moment but very early these situational engrams repeatedly go beyond the inevitable dialectic that exists between bodily sensations and their counter-impulses. The memory trace (Erinnerungsspur) is more than the consequence of a simple process of stimulus-response; in itself it already has sensorimotor qualities. A simple illustration of this scenic composition of sensorimotor experience formation is to be found in the banal fact that the stimulus is sure to provoke its reaction. For example, the noise of a mouse 'results' in the cat turning its head.

3. And the foundation for all this is in, the scenic unity between the 'inside' and 'outside', between the organism and its environment .... This interplay is the foundation for everything. It remains the basic model, from which we will also later have to depart. (Lorenzer, 1986, p. 43)

The scene is thus shaped by the bodily referent inherent in it from the outset. A child's earliest perception, no doubt while still in the womb, is a holistic experience. The perceptive instruments are an ensemble of receptors which give the external world in intra-psychical space a scenic structure. The bodily processes described by Lorenzer should not, however, be seen as natural or ingrained reflexes, even if they seem quite similar. The senso-motoric process can be readily recognized in a nursing mother whose milk production is activated the moment her child cries and not when the hungry child starts to suck at her breast. The baby's interactive need, the stimulus, is perceived and understood by the mother as a holistic experience, and her body responds immediately - holistically, scenically and faster than it could ever be triggered by any conscious decision. But they are learned in social interaction.

Hence, this describes the scenic unit between the organism and its environment. The scene always encompasses both, 'internal' and supports the statement that "this interplay is the foundation for everything". Such interplay provides the basis for human experience, it remains both active and necessary one's whole life long and constitutes an ever-more discerning ability to take in new experiences. 
Let us concentrate on the original experience: the scenic interplay and its effect on human development. This interplay, whether occurring within pre-natal, post-natal or familial constellations, has two fundamental qualities: satisfying and unsatisfying/harmful. In consequence, human development occurs against the background of 'ananke', the basic human state of vulnerability. Humans in particular are dependent on a constantly flowing and satisfying exchange with their environment. This is very obvious at the outset of life, but it continues thereafter .... This state of dependency keeps this interplay going and pushes it in the direction of the satisfaction of needs. Long before this compass orientating us to the satisfaction of needs is laid down, there still exists a requirement that needs are met. The basic human state of vulnerability is the source of the drive towards exchange and interplay: the first fundamental content of this drive is directed towards satisfying interactions and the defense against unsatisfying and damaging ones. The drive is therefore the urge both to accept and seek out specific interactions fulfilling and satisfying needs. It is clear that such requirement and needs have their origin in bodily metabolism. The need for human contact evolves from this. Sexual needs bear witness to these bodily origins. (Lorenzer, 1986, p. 44)

Lorenzer defines drive as the ensemble of all efforts to achieve satisfaction. This satisfaction is only achievable in social relationships - also for the most basic biological needs. The active search for satisfying interaction with the social environment, including specific individuals with whom a relationship is formed, shapes a structure of 'specific interaction forms'. It is the memory traces of satisfying experiences which, in interplay between 'internal' and 'external', achieve their unmistakable form and subsequently become an ensemble, a formation. Lorenzer maintains the biological dimension of the drive theory by emphasizing the pleasureunpleasure principle. At the same time he integrates the theory into a new view of early social interactions whose ongoing importance he develops in the interplay between the internal and external, between biological needs and the social forms in which they can be satisfied and are reconfigured.

This dialectic gives rise to the life-long development dynamic of the subject in interaction with other subjects and the world.

But at what point does language come into the game? The early pre-verbal, scenically stored interaction experiences, the 'specific interaction forms', gradually include verbal images which appear in the interaction. Simple (presymbolic) interaction forms and spoken words, which are in themselves holistic and situated entities of meaning, defined in social interaction, are the material for the development of a symbolic level. Alfred Lorenzer takes up this link between interaction form and verbal images, as a process of symbol-building and emphasizes that:

Again: word and interaction together construct the language symbol. Therefore I have called this a 'language symbolic interaction form' (Sprachsymbolische 
Interaktionsform). When word and interaction are joined in this way, practice is - via language - fully at our disposal. (Lorenzer, 1986, p. 50)

The 'power of language to regulate practice' when oriented outwardly encompasses what we term 'action' or 'conscious perception'. However, the 'power of language to regulate practice' when oriented inwardly, also encompasses 'internal reflection', 'conscious emotion' etc. In relation to the task of psychoanalysis, we can now begin to see what is meant by 'language destruction and reconstruction': the separation of the unit of language and practice and conversely the therapeutic attempt at their restitution (p. 51). Only when a complex of sounds has found its appropriate place in the context of the language-sign, and the syntactic level of language links with the pragmatic and semantic nature of language, only when this is accomplished has a full language figure (Sprachfigur) that corresponds with the scenic practice figure been established (1986, p. 52).

When the interaction form in this way is symbolically expressed and thus gains access to the conscious it enables reflection on one's own behavior and provides the conditions necessary for reasoned tentative action. Only with language does this become clearer: language symbolic interaction forms integrate social practice in a more comprehensive and differentiated organization framework.

This notion leads directly to the concept of the language game Lorenzer developed after Wittgenstein. The latter defined the language game as a dialectic unit of life practice, language use and world view (1953). Wittgenstein's language game notion was in fact primarily critical to previous philosophical ideas of language and scientific statements, seeing language meaning as a result of language use and the social practices in which language use is inscribed. Lorenzer expands this notion by incorporating unconscious dimensions which were not addressed in Wittgenstein's concept. He sees the language games not as mere conventions but as dynamic result of a negotiation between language user with different experiences and practices, and hence based in these social practices. With Lorenzer's extension it means that this negotiation also involves non- and pre-verbal experiences and also harbors elements that are products of a destroyed symbolization of experience. Language as an instrument of symbol-building is not simply based on the presymbolic interaction form, but actually contains it. For this reason the pre-symbolic interaction form remains virulent one's whole life long, is inseparably linked to subsequent, development history-related verbal expression or, being excluded from the language symbol spectrum, seeks out other-than-verbal ways of finding expression. Today, it is not only clinicians but also social researchers who describe this form of active expression as 'enactments'. They are the unconscious, soulless repetition of interaction experiences that the subject, either in times of great need or in response to emotional pain, has tended to separate, disassociate or repress. While they cannot, therefore, be integrated into the individual processing and development process, they nonetheless shape that process. 
If, as described earlier, the early interaction experience cannot be symbolized it still remains an action-driving component of the individual-subjective structures and their experience forms. How it differs from symbolized, verbal forms is seen in the subject's inability to reflect on those experience forms. The subject is not able to draw upon practice through language. At the same time, as Lorenzer repeatedly emphasizes, the non-verbal interaction form is always linked to subsequent language symbolic forms. The ability to express one self verbally and pre-verbally involves many other aspects. The language game as a concept to identify conflict dynamics in this dual perspective of social and individual is presented in one of Lorenzer's earlier works as follows:

The term 'language-game' is productive in a number of ways:

a. As a category it refers to human 'character' rather than describing human behavior. More precisely, the model of the language-game characterizes individual structures as sedimented versions of concrete interactions (as symbolic interaction forms), including the basic elements of both language and action.

b. Understanding the constitution of the basic elements of language and action renders visible the individual structure as the outcome of a specific production process called 'socialization'. This enables us to see configurations of consciousness, as well as early drafts of future action (Handlungsentwürfe) as a synthesis of nature and societal practice.

c. When integrated into a theory of individual structures, the model of the language game - embracing its constituents practice and language - provides us with a useful backdrop that renders visible what was previously opaque, namely the active making of configurations of consciousness as they emerge in practices (both being realized in concrete interactions) (Lorenzer, 1977, p. 34ff).

The term language game thus refers to three dimensions of the social: the individual structure of the subjective, the socialization process and general Social practice. In Lorenzer's work, we learned that individual structure is expression of real interaction experiences from early life onwards. Social experiences in their ongoing production process constitute behavioral patterns which can be generalized. Through conscious verbal action, these also bring a social practice to light on which they are also based. Language games can thus only be understood in their social context. They assume a common practice-based agreement on meaning and are always the result of social practice Lorenzer, 1970b). If the language game is the link between a specific interaction form and a language figure, then potential disturbances and interferences in the language game can be identified. The symbolic unit is dissolved when it is subject to repression.

When the word is separated from the interaction engram the latter once again becomes an unconscious interaction form. The word, for its part, loses its relation to sensual practice, it becomes emotionless, an empty sign. Thus the interaction engram becomes unconscious again losing all the characteristics 
which it had gained from its relation to the word, i.e. through its introduction into the meaning system of language. In other words, what is lost is: the capacity to reflect upon behavior patterns; and the capacity to 'try things out' (and thus make meaningful interventions in stimulus-response behavior) and to judge actions in a realistic way. ... The de-symbolized language signs suffer the opposite fate. They remain in the conscious, where they can be easily manipulated because they have been freed from their relation to practice figures. In this state, they are nothing more than calculation and cold-rational behavior, no longer capable of embodying the specific quality they originally contained and that was originally experienced. (Lorenzer, 1986, p. 53)

Lorenzer describes the characterized division between words and interaction forms in previously established language games as the destruction of language. The destruction of this symbolic unit reverses symbolization, hence the term 'desymbolization', and it may occur during (subjective) conflicts later in life. This means that once achieved, the ability to symbolize (verbal expression of a subjective structure) is withdrawn in relation to a specific problem which the individual experiences as an inner conflict. The ability to express an experience or an emotional process in words is lost in connection with the issue causing the conflict. Conflict in this sense is seen as the situated clash of irreconcilable, contradictory interaction forms.

Interaction forms which are symbolized in language figures can thus be reexcluded from the language context. This happens with the aid of resistance mechanisms: by repressing them, they are excluded from the conscious relationship between language and practice. Although this turns them back into unconscious interaction forms, the very fact of this reversion allows them to retain their energetic, dynamic relevance. They act as behavior drivers, albeit in the form of blind action and reaction which is not open to conscious self-reflection. For the individual, the recurring unconscious reenactment of a scene whose structure is similar to the actual conflict, appears in the form of need for repetition.

Symbolization through language has the advantage of being brought to mind independently of the real situation and thus fulfills an important function in the regulation of emotion. In other words, it assists the subject's independence (tentative action, hesitation). By separating the language from the interaction form, the person is again made dependent from the effects of unconscious conflict. He or she rarely has the power to free themselves from the dynamics of the unconscious scenic processes. This is in worst case the type of problems in the clinical psychoanalysis from which Lorenzer starts his theorizing.

The described division of the symbolic unit in the language game is evident in the context of spoken language, in texts and in interviews. It is expressed in the structures of a text and is characterized by the fact that it excludes the interaction partner, say the interpreter of an interview transcription, from the direct understanding. The spoken 
word is no longer understandable for the listener or reader. The societal reference of collective meaning dimensions and a social meaning is interrupted.

So which forms of understanding might provide access to such destroyed, desymbolized language figures? A means of access is needed that reidentifies the scenic unit, including when there is no or only an altered form of verbal expression because the unit of language symbolic and interaction form has been lost. This is where Lorenzer's idea of scenic understanding has its methodological significance.

\section{SCENIC UNDERSTANDING}

The basic methodological idea in Lorenzer's long intellectual journey, and particularly when he summarized his ideas in 1986, was the possibility to learn from the type of hermeneutic process in psychoanalysis for the analysis of cultural phenomena.

In the psychoanalytic process, all understanding centers on and is related to the mode of 'scenic understanding'. In this mode understanding is attuned to two specific objects: the 'scenic drafts', i.e. the 'interaction forms' of the analysand. Particularly herby psychoanalysis provides us with a model example. If we want to understand the analysand's life-practice, which does not exclude his concrete social reality, we must follow the path laid down by his subjective phantasies and outlines of relations. This means we must become attuned to his scenic interaction forms as these unfold before us. (Lorenzer, 1977, p 125)

What in this quotation is described as a therapeutic approach in the analyst's consultation room can be transferred to understanding texts, language and human behavior. Immediately, the question arises as to how a mode of understanding can be practiced which explores the scenic in a non-clinical context. Lorenzer and his colleagues have demonstrated the approach in relation to literary texts and cultural phenomena (Lorenzer, 1986; Prokop, Friese, \& Stach, 2009), and we have taken it a bit further into qualitative social research in a number of more profane contexts. In the following I shall discuss the methodology of scenic understanding and its practical implementation. In other words, how could qualitative social research understand unknown subjective content and processes which include the unconscious and draw attention to non-verbal messages.

Like every hermeneutic approach it is about understanding the meaning in agency and expressions, and in practical social research. Although some measures can be taken to make the data suitable scenic understanding can be applicable to almost any text or phenomenon referring to agency and subjective expression. The prototypical material is, though, a text, or can be seen as a text. More exotic ways of producing the data in the first place are videos or conversations held while observing videos (second order field observation). Very often the text is a transcript of a focus group discussion or thematic group discussion. In other cases it may be an interview individual or collective - or it may be a field diary from an observation. 
To identify the meaning structure of a text, we may distinguish different levels of interpretation:

1. The obvious referential content of the text: What is being talked about?

2. How do people talk to one another? This question on the metacommunicative content of a text takes us to the level of scenic understanding

3. Why are the characters talking in precisely this way? How can we understand it by means of theoretical knowledge combined with background factual knowledge? The first of these steps is the same as in most types of qualitative method.

The 3 step might in its form remind about an explanatory approach which seeks a causal or rule-based understanding. Since it is a hermeneutic methodology it is not, instead it is a more comprehensive multilayered interpretation enabled by step 2 . The 'scenic understanding' focuses on the ongoing tense relation between the manifest and the unconscious meanings of a text which requires an imagination of the unconscious that we can imagine as a collective reservoir of culturally rejected patterns, forbidden yearnings and suppressed desires. In-depth hermeneutic interpretation thus focuses on the characters in the relationship described in the text and on the dynamics of the relationship between a text and its interpreter(s) in order to trace the subjective structure of cultural constraints.

The reference point in the scenic interpretation is the language used in the text, with particular attention being placed on how scenes in the text point to unexpressed desires and tensions, on how the text arranges 'forms of communication which makes the unspeakable' understandable, or "secures it an un-negligible position in public space" as Lorenzer says about the task of the poet (1986, p. 24). The initial reading seeks to apply the same type of freefloating awareness ('gleichschwebender Aufmerksamkeit') as is known from the clinical situation: one's own reactions and irritations are noted without coming immediately to any particular conclusions or forming theoretical definitions. Indications of such hidden conflict dynamics include gaps, inconsistencies, unusual use of language, jumps in the story or sudden changes of subject, and remarkable ways of relating to the subject or to each other (in case of group interaction texts). But also the reactions, emotional states and associations of the readers/interpreters may be indications of the dynamics we are looking for even if you cannot immediately understand them. Practically an interpretation procedure is most often organized in a group. Some procedures go line by line, seeking to understand each unit of text, and revising the understanding gradually as the later segments are taken into consideration. Other procedures start by an open conversation conveying 'first impressions' and reactions from the members of the interpretation group. In some cases you will experience that controversies and conflicts arise within an interpretation group, evoked by the text. Using these observations and reactions as a base, particularly powerful passages are subjected to in-depth analysis in interpretation groups. What has already been described as the transference between the individual reader and the text is now transferred to a collective understanding process: the transference and counter-transference 
dynamics multiply. This procedure may lead very directly to 'holistic' but preliminary interpretations that are set under discussion, or it may produce several 'loose ends'. The interpretation discussion most likely includes reference to the concrete text and its manifest meaning, and it may very well also draw on theoretical frameworks and on background knowledge which in the first place may support or contradict the interpretations suggested. The discussion gradually moves into a validation discussion. In principle the validation will refer to usual criteria and procedures for validation of qualitative analysis. In the first place it will refer to the manifest text on the one side, and a theoretical reflection of the whole complex of subjective agency and expression in the text and in the relation between the text and the interpreters.

The assumption of unconscious meaning components makes the language game an instrument with which to analyze individual structures and to identify collective social processes. Language figures and language symbolic interaction forms always possess a social character which goes beyond the individual, because they assume social understanding processes within the language community. As a result, they can be analyzed for the social meaning they contain and give an insight into the social configurations and their unconscious, not-yet-conscious component. This is the methodological bridge which enables the unconscious dimensions of experience to be accessed from language.) They can also be observed from the subjective perspective of the speaker and shed light on the individual meaning contained in a specific scene. The language figure then reports on the subjective structures and the associated experiences of social life practice.

As we were reacting on the remarkable behavior of Lou in the illustration example, led into both an individual psychological reductive interpretation, and into a cultural criticism against the seductive effects of TV shows like Big Brother. We resisted those temptations because we, led by the theoretical points of Alfred Lorenzer, to develop a more comprehensive psychosocietal interpretation. An interpretation which does not exclude some regressive aspects in the TV audience, and definitely does not exclude a critique of the quality and the political dimensions of the TV shows. But we wanted to find the collective or societal unconscious mechanism that the show (re)activates in Lou as in everybody else, and we wanted to understand why this led her to act in this enraged and seemingly irrational way - and in this sense we also wanted to rehabilitate the subject in relation to her violation of good civil behavior, assuming that she was enacting something that was collective and could not be explained and reasoned. Referring to Lorenzer's development of the language game concept we would seek to trace the relation between the manifest language meanings in her account, the societal meanings that are relegated to unconscious interaction forms pushing on conscious recognition - and the wider societal practice in which the language use makes sense.

A lot of energy in the story told is condensed in Lou's sentence: "I just wanted her out" - Lou's emotional engagement seems condensed in it, and the plot of the scene seems driven by, or explained by, this sentence. 
On the one hand the words seem harmless. They refer to the rules of games which are in broad use and enjoy great social acceptance. Through play, children learn that while it is good to win, being a good loser takes far more dignity and courage. It is a standard pattern in the type of TV shows to which Big Brother belongs, and has spread to be one of the standard storylines of so called interactive TV broadcasts.

On the other hand Lou's words supported by characteristic behavior which gives the spoken words an explosiveness which seems - guided by the theory of interaction forms and language - to indicate a further meaning than the immediate referential one: The scene that Lou describes (which is told as having taken place in the recent past) seems to have harbored a trigger stimulus which forced Lou to act impulsively. Her behavior seemed designed to ensure that another person be excluded and punished. On the psychological level violence replaces symbolic reflection. This behavior, within a classical psychoanalytical horizon, recalls the link between oedipal conflict issues from the childhood: the daughter wants to push the mother out to more easily gain the father's favor. The intruder is to be destroyed. Lou might have such an individual version of a standard socialization experience. Although convenient, this dramatic constellation from each childhood triangularization phase would be reductive and not lend a cultural analytic perspective to the understanding. Instead we should look for a potential correspondence between the individual subjective dynamic and societal meanings that are implicitly present in the social setting of the TV show. We are looking for the supra-individual, societal meaning of the story Lou tells, although indirectly. The analysis so far seemed to show that the TV show (cultural meaning) elicits unconscious desires and identifications (interaction forms) which influence the agency and produces an intense ambivalence. The reconstruction of this ambivalence should help reveal the unconscious in the text.

If we recall the interpretations used at the beginning of this chapter, the dynamic of inclusion and exclusion runs through all interpretations of the text sequence. The TV games are about excluding others, exclusion is an important part of the game. This is bound up with the setting of norms which sanction the exclusion of others. The mass viewer participation seems to indicate not only social acceptance but also a widespread need to be included in the game of excluding others. Lou serves as an exemplary viewer and contestant - she stands for more than just herself, in that her reaction is representative of the desired inclusion of viewers in the game. It seems justified to see Lou's actions and the key statement as part of a language game in Lorenzer's sense - combining the explicit and manifest meaning with experiences of winning inclusion by joining the exclusion of others, and a societal perspective in a neo-liberal society where separation prevails over integration. But we may also interpret her reactions so that the participation in this language game elicits ambivalent feelings. We can relate it to the moral paradox that the exclusive action is justified by the defense for the moral integrity in the community in the TV show container.

With the positive evaluation of what is generally seen as negative behavior (exclusion), a door is opened to are judgmental and stereotypical attitudes everyday 
life which allow the unknown and the foreign to be negated without punishment and eventually to be eliminated. The definition of foreign, unknown elements as a justification for exclusion is reminiscent of the well-known studies on the social function of prejudices (Adorno, Aron, Levinson, \& Morrow, 1950), in which projective power serves in shifting everything one dislikes in oneself onto another group and then combating it in that group. The dynamic of exclusion can take the form of collective violence if it is not harnessed and is allowed to develop uncontrolled.

Thus, the sentence "I just wanted her out" becomes a battle cry in a fight against the undesirable and alien. The vehemence with which it is spouted reveals its individual emotional foundation - the exclusion of the undesirable serves the defense of the individuals own boundaries, the collective self is stabilized through projective stigmatization of the other and the subsequent exclusion of a person deemed foreign and strange. The mass reception of such TV-shows seems to point to the societal strength of a language game - a combination between language use, outlines of life practice and a world view in which the identification with one's own group is based in excluding others who are deemed 'strangers'. A collectively fascinating TV game which not only uses this projection mechanism but nurtures it under greenhouselike conditions helps foster general acceptance of archaic, collective defensive formations. The consciousness and norms which are communicated no longer need be subjected to conscious, reflective reality checks. Through mass fascination and the social practice it is based upon, it appears adequately legitimated.

When we finally returned to the relation of the interpretation group: Do we also have a share in the exclusion game? The individual 'clinical' interpretation of the case can be recognized as a defense against the collective regression whose analysis triggered outrage among the interpreters themselves. Whereas the interpretation of an immature, oedipal conflict constellation or an unguided individual loss of control based on a simple identification appears quite harmless. Recognizing the collective nature of the unspoken interaction forms, and the ambivalence in Lous actions also makes visible that she is actually also - utopian? - longing for community and integration.

In our fellow interpreters' account (Bereswill, Morgenroth, \& Redman, 2010) you can see this interpretation presented with a main emphasis on the process in the interpretation community and the interplay between the scenes in the TV-show, the scene in which Lou acts, and the scene of interpreting. This is illustrating the methodological point that the transfer/counter-transfer between interpreters and text take advantage of the scenic imagination. Here we emphasize the aspect of theoretical guidance because the theoretical framework and the psychosocietal methodological ambition - including Lorenzer's notion of the collective unconscious and the scenic - really were imperatives which helped the interpreter group to look for the traces of the extended language game in the text which did not appear easily. And we think this is an essential lesson for doing psychosocietal research. 


\section{AN EPISTEMOLOGICAL PERSPECTIVE: PSYCHOANALYSIS, LANGUAGE AND KNOWING}

Alfred Lorenzer's contribution enriches the interpretational social science with a new theory and some practical inspiration for dealing empirically with the subjective aspects of social agency and interaction. This is in itself highly appreciated. Many qualitative methods tend to take their informants/ narrators/sources for granted, and to neglect the involvement of the researcher subject as well. Others emphasize the need for researcher self reflection but do not provide appropriate tools for doing so. Lorenzer, among others, problematizes the subject category - both the subjects in the text and the subjects who are researching by redefining the need for reflection into an empirical issue. But he goes one step deeper in theorizing societal framework of understanding the subjects - or rather the subjectivities. In this way it also seems as if he avoids the risk that made Berger and Luckmann (1966) warn so strongly against the alliance with psychoanalysis, the risk of reducing subjectivity to a mechanical 'natural' causality. It seems that his consequent material and endogenous notion of the unconscious enables a clearly hermeneutic stance without giving up the bodily dimensions of the human subjectivity.

Berger and Luckmann's (1966) comments are particularly interesting because their book has been assigned the honor to be the first main work of constructivism. Both Lorenzer and Berger and Luckmann anticipate the poststructuralist critique of Marxism. And we think that Lorenzer - being one of the psychoanalysts that Berger and Luckmann (1966) warned against - exactly produced an alternative answer to their ambition of unified social theory theorizing the agency-based (re)production of societal structures.

It is contested if Berger and Luckmann's book actually belongs to the tradition of social constructivism (Collin, 2002), but at least it has been possible to interpret it into that framework. It seems more appropriate to see their book as a precursor, which made visible the wider consequences for social theory of theorizing knowledge as a societal phenomenon. (North American) constructivism has developed this into an epistemology in which the role of culture/knowledge/discourse surmounts the role the subject as well as the societal object.

Lorenzer's work indicates a different possible continuation of Berger and Luckmann's story. We may see a psychosocial theory of the subject and the role of language in subjectivity as a foundation for a parallel materialistic constructivism, with the social philosophy of the Frankfurt School in several generations as a backbone (Adorno, 1976). Lorenzer also takes over the Wittgensteinian notions of language use and language games, and anchors them in the socialization and the mediation of societal culture which for the individual may take conscious as well as unconscious forms. Applying this extended notion of language use and language game to epistemological issues offers a way around the relativist excesses of some contemporary constructivism by redefining the relativity issue into an empirical one. 
The conception of subjectivity still differs widely between North American traditions, in which Mead is still a both representative and distinguished figure, and a psychosocietal conception. A contemporary discussion of the relation between Mead and Lorenzer's psychoanalysis would be really interesting. Adorno's theoretical integration of psychoanalytical theory into sociology was connected with the need to understand the psychic mechanisms which enabled the political success of Nazism. Adorno in his own empirical research into the social psychology of authoritarianism provided a timely case for this interrelation (Adorno et al., 1950). In order to understand in which way the particular is mediated through, but not determined by, the societal whole you need to understand and examine empirically also the dynamics of the individual psyche - as a mediation of societal relations. Psychoanalysis was offering a theoretically developed and empirically specified research into the psyche, and the interrelations between body and (certain aspects of) consciousness but it needed a reconceptualization in sociological context - reinterpreting psychic dynamics as mediations of societal relations - and that is to say a social psychology of culture - with implications also for (scientific) knowledge.

Lorenzer's particular contribution is first that he presents a theory of the materiality of endogenous societal alternatives. Second the development of interpretive methods building on psychoanalysis and hermeneutic text interpretation enabled an empirical study of how the dynamics of knowing on the social level could be connected with the dynamics of inner psychic experience.

\section{ACKNOWLEDGEMENTS}

This chapter is partly based on a draft paper jointly authored with Mechthild Bereswill, Christine Morgenroth, and Peter Redman, as explained in the text. Quotations from Alfred Lorenzer: 'Tiefenhermeneutische Kulturanalysen' (1986) are taken from a translation by Bereswill and Morgenroth, unless other notice is given. We would like to thank especially professor Birger Steen Nielsen, Roskilde, for comments on earlier drafts and for help in the understanding of Lorenzer.

\section{REFERENCES}

Adorno, T. W. (1967). Sociology and psychology (Part 1). New Left Review, 46, 67-80.

Adorno, T. W. (1969/1976). The positivist dispute in German sociology. London: Harper Torchbooks. (Originally published in 1969, Der Positivismusstreit in der Deutschen Soziologie)

Adorno, T. W., Aron, B., Levinson, M. H., \& Morrow, W. (1951). The authoritarian personality. New York, NY: Harper and Row.

Bereswill, M. (2008). Gender and subjectivity in the interview situation: A critical discussion. Psychoanalysis, Culture \& Society, 13, 316-324.

Bereswill, M., Morgenroth, C., \& Redman, P. (2010). Alfred Lorenzer and the depth-hermeneutic method. Psychoanalysis, Culture \& Society, 15(3), 221-250.

Berger, P., \& Luckmann, T. (1966). The social construction of reality. A treatise in the sociology of knowledge. Harmondsworth: Penguin.

Collin, F. (2002). Social reality. London \& New York, NY: Routledge. 


\section{SOCIALIZATION, LANGUAGE, AND SCENIC UNDERSTANDING}

Erikson, E. H. (1950). Child and society. New York, NY: Norton.

Freud, S. (1891/1953). On Aphasia: A critical study. New York, NY: International Universities Press.

Freud, S. (1915/1957). The unconscious (Standard Edition, 14, pp. 159-204). London: Hogarth Press.

Leithäuser, T. (1976). Formen des Altagsbewusstseins [Forms of everyday life consciousness]. Frankfurt/M: Campus.

Leithäuser, T., \& Volmerg, B. (1988). Psychoanalyse in der Sozialforschung [Psychoanalysis in social science]. Opladen: Westdeutscher Verlag.

Leuzinger-Bohleber, M. (1998). Wo bleibt das Gedächtnis? Psychoanalyse und embodied cognitive science im Dialog [Where will the conscience go? Psychoanalysis and embodied cognitive science in dialogue]. In M. Koukkou \& M. Leuzinger-Bohleber (Eds.), Erinnerung von Wirklichkeiten: Psychoanalyse und Neurowissenschaften im Dialog (pp. 517-589). Stuttgart: Verlag Internationale Psychoanalyse.

Lorenzer, A. (1970a). Zur Kritik des psychoanalytischen Symbolbegriff [Critique of the psychoanalytic concept of symbol]. Frankfurt/M: Suhrkamp.

Lorenzer, A. (1970b). Sprachzerstörung und Rekonstruktion: Vorarbeiten zu einer Metatheorie der Psychoanalyse [Language destruction and reconstruction]. Frankfurt/M: Suhrkamp.

Lorenzer, A. (1972). Zur Begründung einer Materialistischen Sozialisationstheorie [Foundations of a materialist theory of socialization]. Frankfurt/M: Suhrkamp.

Lorenzer, A. (1974). Die Wahrheit der Psychoanalytischen Erkenntnis: Ein HistorischMaterialistischer Entwurf [The truth of psychoanalytic knowledge]. Frankfurt/M: Suhrkamp.

Lorenzer, A. (1977). Sprachspiel und Interaktionsformen: Vorträge und Aufsätze zu Psychoanalyse, Sprache und Praxis [Language game and interaction forms]. Frankfurt/M: Suhrkamp.

Lorenzer, A. (1981/2002). What is an unconscious phantasy? (pp. 29-41, Tobias Schaffrik, Trans.). Retrieved April 30, 2010, from http://bidok.uibk.ac.at/library/schaffrik-lorenzer-work-e.html

Lorenzer, A. (1986). Tiefenhermeneutische Kulturanalyse. In: A. Lorenzer (Ed.), KulturAnalysen: Psychoanalytische Studien zur Kultur [In-depth hermeneutic cultural analysis] (pp. 11-98). Frankfurt/M: Fischer.

Lorenzer, A. (2002). Die Sprache, der Sinn, das Unbewusste: Psychoanalytisches Grundverständnis und Neurowissenschaften [Language, meaning, the unconscious]. Stuttgart: Klett-Cotta.

Lorenzer, A. (2006). Szenisches Verstehen. Zur Erkenntnis des Unbewußten [Scenic understanding. On recognition of the unconscious]. Kulturanalysen Band 1, herausgegeben von Ulrike Prokop und Bernhard Görlich. Marburg: Tectrum Verlag.

Mitscherlich, A. (1963). Auf dem Weg zur Vaterlosen Gesellschaft [Towards a society without fathers]. München: Piper.

Morgenroth, C. (1990). Sprachloser Widerstand: Zur Sozialpathologie der Lebenswelt von Arheitslosen [Resistance without language: On the social pathology of the lifeworld of unemployed]. Frankfurt/M: Fischer.

Morgenroth, C. (2010). Die dritte Chance: Therapie und Gesundung von jugendlichen Drogenabhängigen [The third chance. Therapy and healing of young drug abusers]. Wiesbaden: Verlag für Sozialwissenschaften.

Parin, P., Morgentahler, F., \& Parin-Mathéy, G. (1963). Die Weissen denken zuviel [White people think too much]. München: Kindl.

Peled, A. (2008). Neuroanalysis: Bridging the gap between neuroscience, psychoanalysis and psychiatry. Hove: Routledge.

Prokop, U., Friese, N., \& Stach, A. (2009). Geiles Leben, falscher Glamour, Beschreibungen, Analysen, Kritiken zu ,Germany's Next Top Model' [Exciting life, false glamour. Description, analyses and critiques of 'Germany's Next Top Model']. Kulturanalysen, 10.

Redman, P., \& Whitehouse-Hare, J. (2008). 'I just wanted her out': Attachment, the psycho-social and media texts. In P. Redman (Ed.), Attachment: Sociology and social worlds. Manchester: Manchester University Press/The Open University.

Salling Olesen, H. (2004). Theorising learning in life history: A psychosocietal approach. Studies in the Education of Adults, 39(1), 38-53. 
Salling Olesen, H. (2007a). Professional identities, subjectivity and learning. In L. West et al. (Eds.), Using biographical and life history approaches in the study of adult and lifelong learning. Frankfurt/M: Peter Lang Verlag.

Salling Olesen, H. (2007b). Theorizing learning in life history - A psycho-societal approach. Studies in the Education of Adults, 1 .

Salling Olesen, H. (2011). Exploraca do sujeito problematico: Historia de vide, subjetividade, experiência de vida [Researching the problematic subject: Life history, subjectivity, life experience]. Educacao, 34(2), 137-146.

Salling Olesen, H., \& Weber, K. (2001). Space for experience and learning. Theorizing the subjective side of work. In K. Weber (Ed.), Experience and discourse: Theorizing professions and subjectivity (pp. 27-58). Roskilde: Roskilde University Press.

Salling Olesen, H., \& Weber, K. (2002). Chasing potentials for adult learning: Lifelong learning in a life history perspective. Zeitschrift fur Qualitative Bildungs-, Beratungs- und Sozialforschung, 2, 283-300.

Schaffrik, T. (2002). The work of Alfred Lorenzer: An introduction. Retrieved April 30, 2010, from http://bidok.uibk.ac.at/library/schaffrik-lorenzer-work-e.html

Stern, D. (1985). The interpersonal world of the infant: A view from psychoanalysis and developmental psychology. New York, NY: Basic Books.

Weber, K. (1996). Experiencing gender: A psychodynamic approach to adult learning - And a case of masculinity and social work. In H. Salling Olesen \& P. Rasmussen (Eds.), Theoretical issues in adult education (pp. 25-40). Roskilde: Roskilde University Press.

Weber, K. (2007). Gender between knowledge economy and everyday life: Change or reproduction? In L. R. West, P. Alheit, A. S. Andersen, \& B. Merrill (Eds.), Using biographical and life history approaches in the study of adult and lifelong learning: European perspectives. (pp. 91-108). Frankfurt/M: Peter Lang.

Weber, K. (2009). Talking about "tacit knowledge": Critical professionalism or collective defences? In L. Thomas, M. Sylke, \& S. Michael (Eds.), Sozialpsychologisches organisationsverstehen (pp. 227-237). Wiesbaden GWV Fachverlage GmbH.

Weber, $K_{-}$(2010). Aggression, recognition and qualification: On the social psychology of adult education in everyday life. European Journal for Research on the Education and Learning of Adults, 1(1-2), $113-130$.

Wittgenstein, L. (1953/2009). Philosophical investigations. London: Blackwell. 